\title{
Factors associated with childhood diarrheal in Ethiopia; a multilevel analysis
}

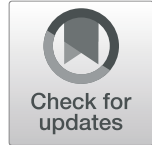

Setegn Muche Fenta ${ }^{*}$ (D) and Teshager Zerihun Nigussie

\begin{abstract}
Background: Diarrhea is the second cause of child deaths globally. According to World Health Organization reports, in each year it kills more than 525,000 children under-5 years. More than half of these deaths occur in five countries including Ethiopia. This study aimed to identify both individual and community-level risk factors of childhood diarrheal in Ethiopia.

Methods: Ethiopian demography and health survey of 2016 data were used for the analysis. A total of 10,641 children aged 0-59 months were included in the analysis. A multi-level mixed-effect logistic regression model was used to identify both individual and community-level risk factors associated with childhood diarrheal.

Result: The incidence of childhood diarrheal was $12 \%$ (95\%Cl: 11.39, 12.63). The random effect model revealed that $67 \%$ of the variability of childhood diarrhea explained by individual and community level factors. From the individual-level factors, children aged 36-59 month (AOR $=3.166 ; 95 \% \mathrm{Cl}: 2.569,3.900)$, twin child (AOR $=1.871 ; 95 \%$ $\mathrm{Cl}: 1.390,2.527)$, birth order 5 and above $(\mathrm{AOR}=2.210,95 \% \mathrm{Cl}: 1.721,2.839)$, not received any vaccination $(\mathrm{AOR}=$ 1.197; 95\% Cl: 1.190,1.527), smaller size of child at birth (AOR $=1.303 ; 95 \% \mathrm{Cl}: 1.130,1.504)$ and never breastfed children (AOR $=2.91 ; 95 \% \mathrm{Cl}: 2.380,3.567$ ) associated with the higher incidence of childhood diarrhea. From the community-level factors, living in a rural area ((AOR $=1.505 ; 95 \% \mathrm{Cl}: 1.233,1.836))$, unprotected source of drinking water (AOR: 1.289; 95\% Cl: 1.060, 1.567) and availability of unimproved latrine facilities (OR: 1.289; 95\% Cl: 1.239, 1.759) associated with the higher incidence of childhood diarrhea. Besides, Children live in Afar, Amhara, Benishangul-Gumuz, Gambella, SNNPR and Dire Dawa regions had higher incidence of childhood diarrhea.

Conclusion: The incidence of childhood diarrhea was different from cluster to clusters in Ethiopia. Therefore, integrated child health intervention programs including provisions of toilet facility, access to a clean source of drinking water, educate parents about the importance of breastfeeding and vaccination have to be strongly implemented in order to reduce the high incidence of childhood diarrhea among children in Ethiopia.
\end{abstract}

Keywords: Diarrhea, Under-five children, Multilevel analysis, Ethiopia

\section{Background}

Diarrhea is defined as the passage of three or more loose or liquid stools per day (or more frequent passage than is normal for the individual). It is usually a symptom of gastrointestinal infection, which can be caused by a variety of bacterial, viral, and parasitic

\footnotetext{
* Correspondence: setegn14@gmail.com

Department of statistics, Faculty of Natural and Computational Sciences, Debre Tabor University, Debra Tabor, Ethiopia
}

organisms. Infection is spread through contaminated food or drinking-water, or from person to person as a result of poor hygiene $[1,2]$.

Diarrhea is the second most common cause of child deaths and the leading cause of malnutrition in children under 5 years old. According to World Health Organization reports, in each year it kills more than 525, 000 children under-5 years, approximately 1439 every day. Fifty percent of the deaths occurred in five countries including Ethiopia. Worldwide, more than 1.7

C C The Author(s). 2021 Open Access This article is licensed under a Creative Commons Attribution 4.0 International License, which permits use, sharing, adaptation, distribution and reproduction in any medium or format, as long as you give appropriate credit to the original author(s) and the source, provide a link to the Creative Commons licence, and indicate if changes were made. The images or other third party material in this article are included in the article's Creative Commons licence, unless indicated otherwise in a credit line to the material. If material is not included in the article's Creative Commons licence and your intended use is not permitted by statutory regulation or exceeds the permitted use, you will need to obtain permission directly from the copyright holder. To view a copy of this licence, visit http://creativecommons.org/licenses/by/4.0/ The Creative Commons Public Domain Dedication waiver (http://creativecommons.org/publicdomain/zero/1.0/) applies to the data made available in this article, unless otherwise stated in a credit line to the data. 
billion cases of childhood diarrheal disease occurred in every year. For instance, about $80 \%$ of morbidity and mortality occur in sub-Saharan Africa and South Asia. Malnutrition is an underlying factor in one third of preventable child deaths and plays a significant role in fatal diarrhea episodes $[1,2]$.

Ethiopia is second country in Africa with the highest number of diarrheal deaths. Diarrhea is the second leading root of death and contributes to more than one in every ten child deaths in Ethiopia [3, 4]. The incidence of childhood diarrhea in Ethiopia was $12 \%[5,6]$. In Ethiopia, the earlier studies indicate that one of the basic health problems of the country was childhood diarrheal $[4,6-9]$.

Several studies have been conducted to examine the determinants of childhood diarrhea in different countries in the world mainly, developing countries including Ethiopia [10-15]. However, in Ethiopia, many types of research have done on institution-based and also are small-geographical areas, focusing on a handful of communities, usually small-sized rural communities $[8,13$, 15-18]. This narrowness might be losing efficient results and invalid conclusions as well as recommendations. Besides, the above studies were taking on individual-level analysis by omitting community (cluster) effect. In the individual-level analysis, the independent assumption among clustered observation may not work and the correlations at the individual level may not work at the community (cluster) level and vice versa. For this reason, it is essential to assess the within-cluster and between cluster level variation, and to estimate the true effect of the above-mentioned factors on multilevel determinants of childhood diarrhea in order to implement more effective future health care policies that target specific units at various levels of the hierarchy and there might be a correlation between the higher levels. Therefore, this study aimed to identify both individual and community-level risk factors of childhood diarrheal in Ethiopia using multilevel analysis.

\section{Methods}

\section{Data source and study design}

A study was conducted in Ethiopia, which is situated in the North-Eastern part of Africa, also known as the horn of Africa. This study used the EDHS 2016 dataset which was conducted by the Central Statistical Agency (CSA). This is the fourth national representative survey done at the country level. The stratified multi-stage cluster sampling was used, and it was intended to be representative at the regional and national level in terms of appropriate demographic and health indicators. In the first stage, 645 clusters of enumeration areas (EAs) (202 urban and 443 rural) were identified using probability proportional to the size of EAs. In the second stage, random samples of 18,008 households were selected from all the identified EAs. Lastly, 16,650 households were successfully interviewed, yielding a response rate of $98 \%$. The primary aim of 2016 EDHS was to provide up-to-date information about the key demographic and health indicators. Both men and women aged $15-59$ years were interviewed. Data was also collected from mothers or care-takers of live-born infants in the 5 years preceding the date of the interview.

\section{Study variables \\ Dependent variables}

The incidence of childhood diarrhea was the outcome variable of this study.

\section{Explanatory variable}

The possible variables associated with childhood diarrhea were categorized as individual and community level factors. Those variables were selected by reviews of the literature reviews $[6,8,9,11,14-17,19-24]$ and their theoretical justification (Table 1).

\section{Data analysis}

The secondary data were recorded in SPSS software version 21 and the analysis was done using $\mathrm{R}$ software version 3.5.3. Descriptive statistics such as frequencies and percentage were used to summarize the sample data. The 2016 EDHS data which have been collected by stratified multi-stage cluster sampling and data are hierarchical (children nested clusters). The individual children are in general not completely independent of each other [5]. Children from the same cluster will be more similar to each other than children from different clusters. This leads to having too small estimated standard errors that produce spurious 'significant' results. Since, clustering effect of the sample should be taken into account during analysis. A multivariable multilevel logistic regression model can account for a lack of independence across levels of nested data [25-27]. For this reason, two-stage multivariable multilevel logistic regression models were used to identify the individual and community level risk factors on childhood diarrhea. The twostage multivariable multilevel logistic regression model written as follows:

$$
\log \left[\frac{\pi_{i j}}{1-\pi_{i j}}\right]=\beta_{0}+\beta_{1} X_{i j}+\beta_{2} Z_{i j}+u_{j}+e_{i j}
$$

Where, $i$ and $j$ are the level 1 (individual) and level 2 (community) units, respectively; $X$ and $Z$ refer to individual and community-level variables, respectively; $\pi_{i j}$ is the probability of develop diarrhea for the $i^{\text {th }}$ child in the $j^{\text {th }}$ community; the $\beta$ indicates the fixed coefficients. Whereas, $\beta_{0}$ is the intercept-the effect on the probability 
Table 1 Independent variables and categorization

\begin{tabular}{|c|c|}
\hline Variables & Categories \\
\hline \multicolumn{2}{|l|}{ Individual level factors } \\
\hline Age of child (months) & $0-23,24-35,36-59$ \\
\hline Sex of the child & Male; Female \\
\hline Birth order & First, 2-3, 4 and above \\
\hline Anemia level & Anemic, not anemic \\
\hline Child is twin & Single, Multiple \\
\hline Place of delivery & Home, health facility \\
\hline Vaccination of child & Yes, No \\
\hline Size of child at birth & Larger than average, average, smaller than average \\
\hline Duration of breastfeeding & Ever breastfed, not currently breastfeeding, Never breastfed, Still breastfeeding \\
\hline Respondent's age (year) & $15-24,25-34,35-49$ \\
\hline Highest educational level & No education, Primary, Secondary and above \\
\hline Family size & $\leq 4,>4$ \\
\hline Wealth index & Poor, Medium, Rich \\
\hline Current marital status & Separated, Married \\
\hline Respondent currently working & Not working, Had working \\
\hline Husband education level & No education, Primary, Secondary and above \\
\hline Number of children & $\leq 3,>4$ \\
\hline \multicolumn{2}{|l|}{ Community level factors } \\
\hline Place of residence & Urban, Rural \\
\hline Region & Tigray, Afar, Amhara, Oromia, Somali, Beninshangul-Gumuz, SNNPR, Gambela, Harari, Dire Dawa \\
\hline Toilet facility use & Yes, No \\
\hline Source of drinking water & Protected, Unprotected \\
\hline
\end{tabular}

of develop diarrhea in the absence of influence of predictors; and $u_{j}$ showed the random effect (effect of the community on childhood diarrhea for the $j^{\text {th }}$ community and $e_{i j}$ showed random errors at the individual levels. By assuming each community had different intercept $\left(\beta_{0}\right)$ and fixed coefficient $(\beta)$, the hierarchical (clustered) data nature and the within and between community variations were taken into account. Four sequential models including the null model were tested: the first model does not include explanatory variables (null model) and only divided the total variance into individual and community component in order to examine the community effect on childhood diarrhea; the second model including only individual-level variables, the third model including only community variables and the fourth model including both the individual- and community-level variables. The results of fixed-effects have been presented in the form of adjusted odds ratios (AORs) with 95\% confidence intervals (CIs). The $P$-value $\leq 0.05$ has been considered as statistically significant. The measures of variation (random-effects) included variance, intra cluster correlation (ICC), a proportional change in variance (PCV), and median odds ratio (MOR). The ICC was calculated to evaluate whether the variation in childhood diarrhea is primarily within or between communities. The ICC was computed by the linear threshold according to the formula used by Snijders and Bosker: $C=\frac{V_{A}}{V_{A}+\pi^{2} / 3}=\frac{V_{A}}{V_{A}+3.29}$, where $V_{A}$ is the estimated variance in each model [28]. PCV is used measure the total variation childhood diarrhea attributed to individual-level factors and cluster level factors in the multilevel mode. It was computed using the formula : $P C V=\frac{V_{A}-V_{B}}{V_{A}}$, where $V_{A}=$ variance of the initial model, and $V_{B}=$ variance of the model with more terms [28]. MOR defined as the median value of the odds ratio between the area at highest risk and the area at the lowest risk when randomly picking out two areas and it depends directly on the community level variance. It was computed using the formula: $M O R=\exp \left(\sqrt{2 * V_{A} * 0.6745}\right) \approx \exp$ $\left(0.95 \sqrt{V_{A}}\right)$, where $V_{A}$ is the cluster level variance [2730]. The existence of multicollinearity was tested by Variance Inflation Factor (VIF) test and variables with value of $>5$ were excluded from the model.

\section{Model fit statistics}

The likelihood ratio test (LRT) to assess the goodnessof-fit between two nested models. Model selection was 
done using Deviance and Akaike's Information Criterion (AIC). The Deviance and AIC were used to compare various candidate models and the model with the minimum deviance and AIC value is considered as a better fit [31].

\section{Result \\ Prevalence of childhood diarrheal and characteristics of study participants}

The overall prevalence of childhood diarrheal in Ethiopia was $12 \%$ (95\%CI: 11.39, 12.63). The highest diarrheal prevalence $(20 \%)$ was in Gambela region, and lowest in Addis Ababa (11.5\%). The prevalence of diarrhea among females (15.6\%) lowers as compared to males (18.4\%). Children living in rural areas were reported to be highly exposed to diarrheal diseases as compared with those living in urban areas (17.7\% versus $14.4 \%)$. Children who never practice breastfeeding were more infected with the diarrheal disease (38.1\%). The highest prevalence of diarrheal disease occurred among multiple birth children (29.5\%). The occurrence of diarrhea higher among children in children age 36-49 month (27.6\%), the smaller size of child at birth(20.7\%), mothers age 15-24 years $(19.2 \%)$, family size less than four(21\%) and primary of the school-educated father(18.4\%) (Table 2).

The majority of children $(58.3 \% \%)$ were born to mothers in the age range of 25-34 years. Eighty-one percent of children were born in a rural area and $6.9 \%$ of children belong to separated women while the remaining 93.1\% were married women. About 97:4\% of children were born in singleton, while only about $2.6 \%$ have been born in multiple twins. More than half, (54.3\%) of children were born from low economic status families, only $32.0 \%$ were from rich and $(13.8 \%)$ were from the medium economic status. About $65.4 \%$ of children were delivered at home, while $34.6 \%$ were delivered in health facilities. Seventy-two percent of children were from a family size of greater than and only twenty-eight from family size of less than four. The majority, (70.6\%) of mothers have used unprotected sources of drinking water (Table 2).

\section{Factors associated with diarrheal diseases among under- five children}

The results of multivariable multilevel logistic regression analysis (fixed effects) were summarized in Table 3 . The model comparison result revealed that model IV is a better fit for the data as compared to other reduced models since it has the smallest AIC and Deviance statistic. In this model, the variable sex of a child, age of a child, birth order, types of birth, and size of child at birth, vaccination of child, age of mother, family size, mother working status, number of U5 children, education level of parents, breastfeeding status, residence, region, toilet facility and source of drinking water were significantly associated with childhood diarrhea. The occurrence of diarrhea among female children were 0.840 times $(\mathrm{AOR}=0.835 ; 95 \% \mathrm{CI}: 0.749,0.931)$ less likely as compared to male children. Children aged 4-5 years old were 3.17 times $(\mathrm{AOR}=3.166$; 95\% CI: 2.569, 3.900) higher risk of developing diarrhea compared to those whose ages were less than 1 year. Those children whose birth order; $2-4$ (AOR $=1.211,95 \% \mathrm{CI}: 1.026,1.429)$ and 5 and above $(\mathrm{AOR}=2.210,95 \% \mathrm{CI}: 1.721,2.839)$ were 1.21 and 2.21 times more likely to develop diarrhea than first order. The likelihood of childhood diarrhea was 1.87 times (AOR $=1.871 ; 95 \%$ CI: 1.390, 2.527) higher for children who have multiple birth types as compared to singleton births. Children who were never breastfed were 2.91times $(\mathrm{AOR}=2.914 ; 95 \% \mathrm{CI}$ : 2.380, 3.567) more likely to develop diarrhea compared to children who were ever breastfed, not currently breastfeeding. Children whose mothers age 25-34 years were $13 \%$ (AOR = 0.872; 95\% CI: $0.744,1.022$ ) less likely to develop diarrhea compared to those children whose mothers age 15-24 years. Besides, children with maternal age 35-45 years were $31 \%(\mathrm{AOR}=0.690$; 95\% CI: 0.547, 0.871) less likely to develop diarrhea compared to those children whose mothers age 15-24 years. Children with secondary and higher maternal education were 0.77 times (AOR $=0.776$; 95\% CI: 0.604, 0.996) less likely to experience diarrhea compared to children whose mothers had no education. Similarly, children with secondary and higher maternal education were 1.22 times (AOR = 1.225; 95\% CI: $1.011,1.484$ ) less likely to experience diarrhea compared to children whose mothers had no education The probability of children's not received any vaccination were 1.21 times $(\mathrm{AOR}=1.197 ; 95 \% \mathrm{CI}$ : $1.190,1.527)$ more likely to develop diarrhea as compared to vaccinated children. Children living in a rural area were 1.5 times $(\mathrm{AOR}=1.505 ; 95 \% \mathrm{CI}$ : $1.233,1.836)$ more likely to experience the diarrheal disease as compared to children living in urban areas. Children live in Afar (AOR =1.205: 95\%CI: 0.924,1.571), Amhara (AOR 1.493; 95\%CI: 1.161,1.921), Benishangul-Gumuz (AOR =1.357; 95\% CI: $1.031,1.787)$, Gambella $(\mathrm{AOR}=1.432 ; 95 \% \mathrm{CI}$ : 1.078,1.902), SNNPR (AOR $=1.609 ; 95 \% \mathrm{CI}: 1.251,2.070)$ and Dire Dawa (AOR $=1.722$; 95\%CI: 1.265,2.342) regions were more likely to be infected by diarrhea as compared to children live in Tigray region. Children use unprotected (unimproved) water 1.3 times (AOR: 1.289; 95\% CI: $1.060,1.567)$ more likely to suffer from diarrhea as compare with a child who uses protected (unimproved) water. Children that were delivered from mothers with no toilet facility were 1.48 times (OR: 1.289; 95\% CI: $1.239,1.759)$ more vulnerable to diarrhea as compared to infants that were delivered from mother with toilet facility (Table 3 ). 
Table 2 Prevalence of childhood diarrheal by background characteristics Ethiopia, 2016

\begin{tabular}{|c|c|c|c|c|}
\hline \multirow[t]{2}{*}{ Background characteristic } & \multicolumn{2}{|c|}{ Total number of Children } & \multicolumn{2}{|c|}{ Diarrheal disease status } \\
\hline & Frequency & Percent & Frequency & Percent \\
\hline \multicolumn{5}{|l|}{ Individual level factors } \\
\hline \multicolumn{5}{|l|}{ Sex of child } \\
\hline Male & 5483 & 51.5 & 1009 & 18.4 \\
\hline Female & 5158 & 48.5 & 806 & 15.6 \\
\hline \multicolumn{5}{|l|}{ Current age of child } \\
\hline $0-1$ & 4054 & 38.1 & 624 & 15.4 \\
\hline $2-3$ & 3856 & 36.2 & 438 & 11.4 \\
\hline $4-5$ & 2731 & 25.7 & 753 & 27.6 \\
\hline \multicolumn{5}{|l|}{ Anemia level } \\
\hline Anemic & 3589 & 33.7 & 613 & 17.1 \\
\hline Not anemic & 7052 & 66.3 & 1202 & 17.0 \\
\hline \multicolumn{5}{|l|}{ Birth order number } \\
\hline First order & 2167 & 20.4 & 399 & 18.4 \\
\hline $2-4$ & 4661 & 43.8 & 779 & 16.7 \\
\hline Five and above & 3813 & 35.8 & 637 & 16.7 \\
\hline \multicolumn{5}{|l|}{ Child is twin } \\
\hline Single birth & 10,363 & 97.4 & 1733 & 16.7 \\
\hline Multiple birth & 278 & 2.6 & 82 & 29.5 \\
\hline \multicolumn{5}{|l|}{ Place of delivery } \\
\hline Home & 6960 & 65.4 & 1184 & 17.0 \\
\hline Health facility & 3681 & 34.6 & 631 & 17.1 \\
\hline \multicolumn{5}{|l|}{ Child vaccination } \\
\hline No & 8187 & 76.9 & 1406 & 17.2 \\
\hline Yes & 2454 & 23.1 & 409 & 16.7 \\
\hline \multicolumn{5}{|l|}{ Size of child at birth } \\
\hline Larger than average & 3214 & 30.2 & 544 & 16.9 \\
\hline Average & 4419 & 41.5 & 649 & 14.7 \\
\hline Smaller than average & 3008 & 28.3 & 622 & 20.7 \\
\hline \multicolumn{5}{|l|}{ Duration of breastfeeding } \\
\hline Ever breastfed, not currently breastfeeding & 5814 & 54.6 & 950 & 16.3 \\
\hline Never breastfed & 575 & 5.4 & 219 & 38.1 \\
\hline Still breastfeeding & 4252 & 40.0 & 646 & 15.2 \\
\hline \multicolumn{5}{|l|}{ Maternal age (years) } \\
\hline $15-24$ & 2575 & 24.2 & 494 & 19.2 \\
\hline $25-34$ & 6201 & 58.3 & 1035 & 16.7 \\
\hline $35-49$ & 1865 & 17.5 & 286 & 15.3 \\
\hline \multicolumn{5}{|l|}{ Highest educational level } \\
\hline No education & 6838 & 64.3 & 1159 & 16.9 \\
\hline Primary & 2678 & 25.2 & 490 & 18.3 \\
\hline Secondary and above & 1125 & 10.6 & 166 & 14.8 \\
\hline \multicolumn{5}{|l|}{ Family size } \\
\hline Less than 4 & 3007 & 28.3 & 632 & 21.0 \\
\hline Greater than four & 7634 & 71.7 & 1183 & 15.5 \\
\hline
\end{tabular}


Table 2 Prevalence of childhood diarrheal by background characteristics Ethiopia, 2016 (Continued)

\begin{tabular}{|c|c|c|c|c|}
\hline \multirow[t]{2}{*}{ Background characteristic } & \multicolumn{2}{|c|}{ Total number of Children } & \multicolumn{2}{|c|}{ Diarrheal disease status } \\
\hline & Frequency & Percent & Frequency & Percent \\
\hline \multicolumn{5}{|l|}{ Wealth index } \\
\hline Poor & 5775 & 54.3 & 995 & 17.2 \\
\hline Middle & 1466 & 13.8 & 260 & 17.7 \\
\hline Richer & 3400 & 32.0 & 560 & 16.5 \\
\hline \multicolumn{5}{|l|}{ Current marital status } \\
\hline Separated & 738 & 6.9 & 145 & 19.6 \\
\hline Married & 9903 & 93.1 & 1670 & 16.9 \\
\hline \multicolumn{5}{|l|}{ Mother's occupation } \\
\hline No & 7683 & 72.2 & 1279 & 16.6 \\
\hline Yes & 2958 & 27.8 & 536 & 18.1 \\
\hline \multicolumn{5}{|l|}{ Husband education level } \\
\hline No education & 4928 & 46.3 & 789 & 16.0 \\
\hline Primary & 3220 & 30.3 & 594 & 18.4 \\
\hline Secondary and above & 2493 & 23.4 & 432 & 17.3 \\
\hline \multicolumn{5}{|l|}{ Number of children } \\
\hline 3 or less & 5435 & 51.1 & 1056 & 19.4 \\
\hline 4 and above & 5206 & 48.9 & 759 & 14.6 \\
\hline \multicolumn{5}{|l|}{ Toilet facility } \\
\hline Yes & 5711 & 53.7 & 942 & 16.5 \\
\hline No & 4930 & 46.3 & 873 & 17.7 \\
\hline \multicolumn{5}{|l|}{ Community level factors } \\
\hline \multicolumn{5}{|l|}{ Place of residence } \\
\hline Urban & 1974 & 18.6 & 285 & 14.4 \\
\hline Rural & 8667 & 81.4 & 1530 & 17.7 \\
\hline \multicolumn{5}{|l|}{ Region } \\
\hline Tigray & 1033 & 9.7 & 172 & 16.7 \\
\hline Afar & 1062 & 10.0 & 200 & 18.8 \\
\hline Amhara & 977 & 9.2 & 178 & 18.2 \\
\hline Oromia & 1581 & 14.9 & 267 & 16.9 \\
\hline Somali & 1505 & 14.1 & 203 & 13.5 \\
\hline Benishangul-Gumuz & 879 & 8.3 & 140 & 15.9 \\
\hline Snnpr & 1277 & 12.0 & 250 & 19.6 \\
\hline Gambela & 714 & 6.7 & 144 & 20.2 \\
\hline Harari & 605 & 5.7 & 107 & 17.7 \\
\hline Addis adaba & 461 & 4.3 & 53 & 11.5 \\
\hline Dire dawa & 547 & 5.1 & 101 & 18.5 \\
\hline \multicolumn{5}{|l|}{ Source of drinking water } \\
\hline Protected & 3133 & 29.4 & 495 & 15.8 \\
\hline Unprotected & 7508 & 70.6 & 1320 & 17.6 \\
\hline
\end{tabular}

\section{Random effect analysis (measures of variation)} The results of the random effects logistic regression analysis presented in Table 4. The empty model (Model I) indicates that there are communities differences in experiencing diarrhea among children. About $22 \%$ of the variance in the odds of childhood diarrhea was attributed to community-level factors (ICC $=22 \%$ ). The MOR (2.56) value of childhood diarrhea was highest in the null 
Table 3 Multilevel logistic regression analysis of individual and community level factors associated with childhood diarrhea in Ethiopia, 2016

\begin{tabular}{|c|c|c|c|c|}
\hline & $\begin{array}{l}\text { Model I } \\
\text { AOR }(95 \% \mathrm{Cl})\end{array}$ & $\begin{array}{l}\text { Model II } \\
\text { AOR (95\% Cl) }\end{array}$ & $\begin{array}{l}\text { Model III } \\
\text { AOR }(95 \% \mathrm{Cl})\end{array}$ & $\begin{array}{l}\text { Model IV } \\
\text { AOR }(95 \% \mathrm{Cl})\end{array}$ \\
\hline \multicolumn{5}{|l|}{ Individual level factors } \\
\hline \multicolumn{5}{|l|}{ Child characteristics } \\
\hline \multicolumn{5}{|l|}{ Sex of child } \\
\hline Male & & 1 & & 1 \\
\hline Female & & $0.835(0.749,0.931)^{*}$ & & $0.835(0.749,0.931)^{*}$ \\
\hline \multicolumn{5}{|l|}{ Current age of child } \\
\hline $0-1$ & & 1 & & 1 \\
\hline $2-3$ & & $0.915(0.765,1.095)$ & & $0.901(0.753,1.078)$ \\
\hline $4-5$ & & $3.213(2.610,3.955)$ & & $3.166(2.569,3.900)^{*}$ \\
\hline \multicolumn{5}{|l|}{ Birth order } \\
\hline first order & & 1 & & \\
\hline $2-4$ & & $1.214(1.030,1.432)^{*}$ & & $1.211(1.026,1.429)^{*}$ \\
\hline five and above & & $2.238(1.743,2.874)$ & & $2.210(1.721,2.839)^{*}$ \\
\hline \multicolumn{5}{|l|}{ Child is twin } \\
\hline Single birth & & 1 & & 1 \\
\hline Multiple birth & & $1.904(1.410,2.572)^{*}$ & & $1.871(1.390,2.527)^{*}$ \\
\hline \multicolumn{5}{|l|}{ Child vaccination } \\
\hline Yes & & 1 & & 1 \\
\hline No & & $1.197(1.012,1.415)^{*}$ & & $1.207(1.190,1.527)^{*}$ \\
\hline \multicolumn{5}{|l|}{ Size of child at birth } \\
\hline Larger than average & & & & 1 \\
\hline Average & & $0.870(0.761,0.994)^{*}$ & & $0.871(0.761,0.996)^{*}$ \\
\hline Smaller than average & & $1.328(1.154,1.529)^{*}$ & & $1.303(1.130,1.504)^{*}$ \\
\hline \multicolumn{5}{|l|}{ Duration of breastfeeding } \\
\hline Ever breastfed, not currently breastfeeding & & 1 & & 1 \\
\hline Never breastfed & & $2.874(2.350,3.516)^{*}$ & & $2.914(2.380,3.567)^{*}$ \\
\hline Still breastfeeding & & $1.189(0.998,1.417)$ & & $1.151(0.965,1.373)$ \\
\hline \multicolumn{5}{|l|}{ Maternal age (years) } \\
\hline $15-24$ & & 1 & 1 & 1 \\
\hline $25-34$ & & $0.850(0.726,0.994)^{*}$ & & $0.872(0.744,1.022)$ \\
\hline $35-49$ & & $0.675(0.537,0.848)^{*}$ & & $0.690(0.547,0.871)^{*}$ \\
\hline \multicolumn{5}{|l|}{ Mother educational level } \\
\hline No education & & 1 & 1 & 1 \\
\hline Primary & & $0.981(0.847,1.136)$ & & $0.987(0.852,1.145)$ \\
\hline Secondary and above & & $0.715(0.561,0.913)^{*}$ & & $0.776(0.604,0.996)^{*}$ \\
\hline \multicolumn{5}{|l|}{ Family size } \\
\hline less than 4 & & 1 & 1 & 1 \\
\hline greater than four & & $0.787(0.682,0.909)^{*}$ & & $0.783(0.678,0.905)^{*}$ \\
\hline \multicolumn{5}{|l|}{ Mother's occupation } \\
\hline No & & 1 & 1 & 1 \\
\hline Yes & & $1.136(1.001,1.289)^{*}$ & & $1.163(1.023,1.322)^{*}$ \\
\hline \multicolumn{5}{|l|}{ Father education level } \\
\hline No education & & 1 & & 1 \\
\hline
\end{tabular}


Table 3 Multilevel logistic regression analysis of individual and community level factors associated with childhood diarrhea in Ethiopia, 2016 (Continued)

\begin{tabular}{|c|c|c|c|c|}
\hline & $\begin{array}{l}\text { Model I } \\
\text { AOR }(95 \% \mathrm{Cl})\end{array}$ & $\begin{array}{l}\text { Model II } \\
\text { AOR }(95 \% \mathrm{Cl})\end{array}$ & $\begin{array}{l}\text { Model III } \\
\text { AOR }(95 \% \mathrm{CI})\end{array}$ & $\begin{array}{l}\text { Model IV } \\
\text { AOR }(95 \% \mathrm{Cl})\end{array}$ \\
\hline Primary & & $0.574(0.528,0.623)^{*}$ & & $0.563(0.502,0.632)^{*}$ \\
\hline Secondary and above & & $0.403(0.363,0.448)^{*}$ & & $0.394(0.364,0.427)^{*}$ \\
\hline \multicolumn{5}{|l|}{ Number of children } \\
\hline 3 or less & & 1 & & 1 \\
\hline 4 and above & & $0.525(0.435,0.634)^{*}$ & & $0.526(0.436,0.636)^{*}$ \\
\hline \multicolumn{5}{|l|}{ Community level factors } \\
\hline \multicolumn{5}{|l|}{ place of residence } \\
\hline Urban & & & & 1 \\
\hline Rural & & & $1.321(1.033,1.689)^{*}$ & $1.505(1.233,1.836)^{*}$ \\
\hline \multicolumn{5}{|l|}{ Region } \\
\hline Tigray & & & 1 & 1 \\
\hline Afar & & & $1.195(1.130,1.902)^{*}$ & $1.205(0.924,1.571)^{*}$ \\
\hline Amhara & & & $1.753(1.370,2.246)^{*}$ & $1.493(1.161,1.921)^{*}$ \\
\hline Oromia & & & $1.212(0.952,1.543)$ & $1.187(0.928,1.518)$ \\
\hline Somali & & & $1.339(1.048,1.709)^{*}$ & $1.238(0.965,1.587)$ \\
\hline Benishangul-Gumuz & & & $1.363(1.043,1.782)^{*}$ & $1.357(1.031,1.787)^{*}$ \\
\hline SNNPR & & & $1.443(1.130,1.844)^{*}$ & $1.609(1.251,2.070)^{*}$ \\
\hline Gambela & & & $1.203(0.911,1.587)$ & $1.432(1.078,1.902)^{*}$ \\
\hline Harari & & & $1.040(0.768,1.409)$ & $1.086(0.797,1.480)$ \\
\hline Addis Adaba & & & $0.597(0.418,0.851)^{*}$ & $0.737(0.513,1.059)$ \\
\hline Dire Dawa & & & $1.839(1.358,2.489)^{*}$ & $1.722(1.265,2.342)^{*}$ \\
\hline \multicolumn{5}{|l|}{ Source of drinking water } \\
\hline Protected & & & 1 & \\
\hline Unprotected & & & $1.414(1.170,1.709)^{*}$ & $1.289(1.060,1.567)^{*}$ \\
\hline \multicolumn{5}{|l|}{ Toilet facility } \\
\hline \multicolumn{5}{|l|}{ Yes } \\
\hline No & & & $1.454(1.221,1.371)^{*}$ & $1.476(1.239,1.759)^{*}$ \\
\hline
\end{tabular}

1 reference category for categorical variable and * reference $P$-value $<0.0001$.

Table 4 Measure of variation on individual and community level factor associated with childhood diarrhea in Ethiopia, 2016

\begin{tabular}{lllll}
\hline Measure of variation & Model I (Null model) & Model II & Model III & Model IV (Full model) \\
\hline Variance (SE) & $0.983(0.041)^{*}$ & $0.424(0.040)^{*}$ & $0.631(.039)$ & $0.326(0.038)^{*}$ \\
PCV (\%) & Reference & 57.07 & 36.01 & 67.04 \\
ICC (\%) & 23.00 & 11.50 & 16.09 & 9.02 \\
MOR & 2.56 & 1.86 & 2.13 & 1.72 \\
Model fit statistics & & & & 8967.384 \\
$\quad$ DIC (-2log likelihood) & 9647.548 & 9004.112 & 9615.004 & 9049.388 \\
AIC & 9651.549 & 9060.113 & 9643.004 & \\
\hline
\end{tabular}

*reference $P$-value $<0.0001$ 
model; this reveled that there was variation between communities (clustering) since MOR was 2.56 times higher than the reference $(\mathrm{MOR}=1)$. Moreover, the highest (67.04\%) PCV in the full model (model IV), showed that about $67 \%$ of the variation in childhood diarrhea across communities was attributed to both individual and community-level factors. The unexplained community variation in childhood diarrhea decreased to MOR of 1.72 when all factors were added to the null model (empty model). This indicates that when all factors are included, the effect of clustering is still statistically significant in the full model (Table 4).

\section{Discussion}

The objective of this study was to identify the risk factors of childhood diarrheal in Ethiopia in Ethiopia using the latest (EDHS-2016) dataset. The prevalence of childhood diarrhea was found to be $12 \%$ (95\%CI: 11.39 , 12.63). The result of this study was higher than the study conducted in Tanzania, 11.9\% [32], and Malaysia,4.4\% [11]. It was also low as compared to finding in Pader District, northern Uganda, 29.1\% [19], Farta District, Northern Ethiopia, 29.9\% [6], Gamo Gofa Zone, Southern Ethiopia,27.5\% [33]. This may be due to the variation in the sample size of the study, socio-demographic characteristics of the respondents, study period, latrine coverage and utilization, access to clean drinking water.

Gambela region had highest level of diarrhea prevalence $(20 \%)$ would attribute to life style of residents, where most of the peoples are pastoralist. Due to their migration from place to place in search of pasture and water, pastoralist may not have access to basic health care, protected sources of drinking water, toilet facility and even not much exposed to medias. There is no permanent home for pastoralist and they practice open defecation. Rivers, streams and wells are the main sources of water; thus they are vulnerable to pollution and diarrheal diseases, particularly children who regularly play in the polluted environment. In contrary, the prevalence of diarrhea was lowest (11.5\%) in Addis Ababa as compared with other regions in Ethiopia. This result may be attributed to exposure of mothers to mainstream medias, accessible to awareness creations of health facilities and non-governmental organizations where most of NGO's are resides in the capital city of the country. Mothers who are in Addis Ababa would have a higher chance of being vaccinated and would have a toilet facility and in addition they would have tape water sources. The prevalence of diarrhea among females (15.6\%) lowers as compared to males (18.4\%). Studies in Ethiopia identified similar patterns of diarrhea among boys than girl [34]. The possible reason might be due to biologic and gender discrimination [34]. It may be that males are more likely to wonder off in unsanitary environment than females. The attribute of this result also needs further investigation.

According to the multilevel logistic analysis indicated, the variation in the childhood diarrhea was attributed to both individual and community level factors. In the final full model (model IV), both individual and communitylevel factors accounted for about $67.04 \%$ of the variation observed for childhood diarrhea. Similar finding also found in Tanzania [35].

Experiencing of diarrhea was significantly associated with sex of child. The occurrences of diarrhea among female children were 0.840 times less likely as compared to male children. This finding is in line with other study findings from Ethiopia [34, 36, 37]. The possible reason might be due to biologic and gender discrimination [34]. The attribute of this result also needs further investigation.

The current age of a child had a significant association with diarrhea occurrence. Children aged 36-59 months were 3.17 times more affected by diarrhea than children age less than 12 months. This is consistent with other studies conducted in Amhara region, Gamo Gofa Zone, Sidama Zone, Ethiopia [6, 8, 33], Tanzania [35], and Northern Uganda [19].

In this study, it was found that there was variation of the diarrhea prevalence rate in terms of child birth order. A higher percentage of diarrhea cases have occurred among the highest birth order. It was found that children whose birth order 4th and above were more likely to be affected by diarrhea than 1st order children. It coincides with the previous studies in which birth order of child increase, the probability of developing childhood diarrhea become increase [9, 20,36].

Regarding the educational level of parents, children of parents with lower education levels were at high risk of developing diarrhea compared to parents with higher education levels. A similar study in Malaysia found that a $7 \%$ higher risk of diarrhea between educated mothers and uneducated mothers and5\% higher risk of diarrhea between educated father and uneducated father [11]. Another study was done in Ethiopia [14, 21, 34] and Uganda [19], showed that had higher education levels of parents significant effect in reducing childhood diarrhea. The possible reason might be due to the fact that education is expected to improve household health-care and hygiene practices. Education might assist parents to obtain knowledge about the transmission and prevention mechanism of diarrhea.

In this study, children born from older mothers were less likely to developing diarrhea as compared to children born from young mothers. This finding is in line with studies done in Tanzania [32]. The possible reason could be the discrepancy in awareness related to prevention and treatment of diarrhea attributable to knowledge 
and information exposure. Older mothers have the potential to gain more information than younger mother about diarrhea from health care providers or other relatives. Households with large family sizes have shown a significant reduction in the risk of childhood diarrhea. This is because member of the family share household duties and mothers have ample time to take care of their children.

The study indicated that the incidence of diarrhea was significantly associated with the duration of breastfeeding. Children who had ever been breastfed had less likely to experience diarrhea as compared to children who had never breasted. This finding had conformity with a study done in Gamo Gofa Zone, Southern Ethiopia [33], Bahir Dar city, Northwest, Ethiopia [4], Medebay Zana district, northwest Ethiopia [13], Ethiopia [34], which showed than children who were partially or not breastfed had a high risk of diarrhea death than exclusively breastfed children. This is because breastfeeding helps to protect child health by preventing contracting contagious diseases including diarrhea.

In the community-level characteristics, the geographical region was a significant predictor of childhood diarrhea. Children living in Afar, Amhara, Benishangul, Gambella, SNNPR and Dire Dawa regions were more likely to be infected by diarrhea as compared to children living in Tigray. This finding is consistent with a study done in Ethiopia [34, 36]. This may be attributed to the large difference in the presence of diarrhea related services including health care, water and sanitation facility and literacy facilities.

Place of residence was a significant predictor of childhood diarrhea in the present study. Children who live in rural areas had higher odds of childhood diarrhea as compared to those children who live in urban. A study in Jamma district, Northeast Ethiopia [21] also showed that the probability of developing diarrhea among rural children higher compared to urban children. This may be due to the people living in rural areas having inaccessibility of adequate facilities such as improved sources of water, sanitation facility, and toilet are some of the consequences. Rural people have not awareness about the transmission, prevention and control of diarrheal disease in comparison to urban people.

This study found that experiencing diarrhea was significantly associated with the availability of toilet facilities in a household. Children that were delivered from mothers with no toilet facility were more vulnerable to diarrhea as compared to children that were delivered from mothers with toilet facilities. This finding is supported by a study done in Gamo Gofa Zone, Southern Ethiopi [33], Jamma district, Northeast Ethiopia [21], Akaki Kality sub-city of Addis Ababa, Ethiopia [38] and North Gondar Zone, Northwest Ethiopia [14, 15], which indicated that children who lived in a household with latrine facility and who defecated in the latrine had lower diarrhea morbidity rate. This may be due that latrine availability reduces fecal environmental pollution and thus decreases the risk of mechanical vectors entering diarrhea-causing organisms to minimize diarrheal disease.

The incidence of diarrhea was significantly associated with a source of water supply. Children from mothers who used unprotected sources of drinking water were more likely to developing of diarrhea as compared to children from mothers who used protected sources of drinking water. This finding is in agreement with a research report from Gamo Gofa Zone, Southern Ethiopia [33], Jamma district, Northeast Ethiopia [21], South Omo Zone, Southern Ethiopia [24] and Malaysia [11], which showed that children use of unprotected water was highly affected by diarrheal. This might be due to the fact that untreated source of drinking water may carry diarrhea-causing pathogens that may lead to diarrhea.

\section{Conclusion}

This study found that both the individual and community factors were associated with childhood diarrhea in Ethiopia. Sex of child, age of the child, birth order, types of birth, size of child at birth, vaccination of child, age of mother, family size, mother working status, number of under-five children, education level of parents, breastfeeding status was significantly associated individuallevel factors with childhood diarrhea. Residence, region, toilet facility, and source of drinking water were significantly associated with community level factors with childhood diarrhea. Therefore, integrated child health intervention programs including provisions of toilet facility, access to a clean source of drinking water, educate parents about the importance of breastfeeding and vaccination have to be strongly implemented in order to reduce the high incidence of childhood diarrhea among children.

\section{Abbreviations \\ AIC: Akaike's information criterion; AOR: Adjusted odds ratio; Cl: Confidence intervals; CSA: Central Statistical Agency; DIC: Deviance information criterion; EAs: Enumeration areas; EDHS: Ethiopian demographic and health survey; ICC: Intra-cluster correlation; MOR: Median odds ratio; PCV: Proportional change in variance; SNNPR: Southern Nations, Nationalities, and People Region; WHO: World health organization}

\section{Acknowledgements}

We would like to thank the Ministry of Health and Central Statistical Agency, Government of Ethiopia, for making the data freely available for research purposes.

\section{Authors' contributions}

SM drafted the proposal, did the analysis, wrote the results, and prepared the manuscript. TZ participated in editing, analysis, and write up of the result. Both authors read and approved the final manuscript. 


\section{Funding}

None.

\section{Availability of data and materials}

The data set was accessed from the Measure DHS website (http://www. measuredhs.com).

\section{Declarations}

\section{Ethics approval and consent to participate}

The study used available secondary data accessed under the National Data Sharing and Accessibility Policy (NDSAP) of the Government of Ethiopia. The data set had no identifiable information on the survey participants; therefore, no ethical approval is required for this work.

\section{Consent for publication}

Not applicable.

\section{Competing interests}

The authors declare that no competing interests exist.

Received: 2 October 2020 Accepted: 22 March 2021

Published online: 06 July 2021

\section{References}

1. WHO, Diarrhoeal disease. 2017.

2. UNICEF, Diarrhoeal disease. 2018

3. WHO, CHERG-WHO Methods and Data Sources for Child Causes of Death 2000-2012. Global Health Estimates Technical Paper. 2014.

4. Dagnew AB, Tewabe T, Miskir Y, Eshetu T, Kefelegn W, Zerihun K, et al. Prevalence of diarrhea and associated factors among under-five children in Bahir Dar city, Northwest Ethiopia, 2016: a cross-sectional study. BMC Infect Dis. 2019;19(1):417. https://doi.org/10.1186/s12879-019-4030-3.

5. EDHS, Central Statistical Agency: Ethiopia Demographic and Health Survey https://dhsprogram.com/publications/publication-fr328-dhs-final-reports.cfm. 2016.

6. Tafere Y, Abebe Abate B, Demelash Enyew H, Belete Mekonnen A. Diarrheal diseases in under-five children and associated factors among Farta District rural community, Amhara regional state, north Central Ethiopia: a comparative cross-sectional study. J Environ Public Health. 2020;2020:1-7. https://doi.org/10.1155/2020/6027079.

7. Fenta A, Alemu K, Angaw DA. Prevalence and associated factors of acute diarrhea among under-five children in Kamashi district, western Ethiopia: community-based study. BMC Pediatr. 2020;20(1):1-7.

8. Melese B, Paulos W, Astawesegn FH, Gelgelu TB. Prevalence of diarrheal diseases and associated factors among under-five children in Dale District, Sidama zone, southern Ethiopia: a cross-sectional study. BMC Public Health. 2019;19(1):1235. https://doi.org/10.1186/s12889-019-7579-2.

9. Shine $\mathrm{S}$, et al. Prevalence and associated factors of diarrhea among underfive children in Debre Berhan town, Ethiopia 2018: a cross sectional study. BMC Infect Dis. 2020;20(1):1-6.

10. Fontoura VM, Graepp-Fontoura I, Santos FS, Santos Neto M, Tavares HSA, Bezerra MOL, et al. Socio-environmental factors and diarrheal diseases in under five-year old children in the state of Tocantins, Brazil. PLoS One. 2018; 13(5):e0196702. https://doi.org/10.1371/journal.pone.0196702.

11. Aziz FAA, Ahmad NA, Razak MAA, Omar M, Kasim NM, Yusof M, et al. Prevalence of and factors associated with diarrhoeal diseases among children under five in Malaysia: a cross-sectional study 2016. BMC Public Health. 2018;18(1):1363. https://doi.org/10.1186/s12889-018-6266-z.

12. Al-Hindi Al. Epidemiology of acute diarrheal diseases among Children under five in Gaza Strip: Post war community based study; 2018.

13. Asfaha KF, Tesfamichael FA, Fisseha GK, Misgina KH, Weldu MG, Welehaweria NB, et al. Determinants of childhood diarrhea in Medebay Zana District, Northwest Tigray, Ethiopia: a community based unmatched case-control study. BMC Pediatr. 2018;18(1):120. https://doi.org/10.1186/s12 887-018-1098-7.

14. Alebel A, Tesema C, Temesgen B, Gebrie A, Petrucka P, Kibret GD. Prevalence and determinants of diarrhea among under-five children in Ethiopia: a systematic review and meta-analysis. PLoS One. 2018;13(6): e0199684. https://doi.org/10.1371/journal.pone.0199684.
15. Getachew A, Tadie A, G.Hiwot M, Guadu T, Haile D, G.Cherkos T, et al. Environmental factors of diarrhea prevalence among under five children in rural area of North Gondar zone, Ethiopia. Ital J Pediatr. 2018;44(1):95. https://doi.org/10.1186/s13052-018-0540-7.

16. Teklemariam S, Getaneh T, Bekele F. Environmental determinants of diarrheal morbidity in under-five children, Keffa-Sheka zone, south West Ethiopia. Ethiop Med J. 2000;38(1):27-34.

17. Mengistie B, Berhane $Y$, Worku A. Prevalence of diarrhea and associated risk factors among children under-five years of age in eastern Ethiopia: a crosssectional study. Open J Prev Med. 2013;3(07):446-53. https://doi.org/10.423 6/ojpm.2013.37060.

18. Girma M, et al. Determinants of childhood diarrhea in West Gojjam, Northwest Ethiopia: a case control study. Pan Afr Med J. 2018;30.

19. Omona $\mathrm{S}$, et al. Prevalence of diarrhoea and associated risk factors among children under five years old in Pader District, northern Uganda. BMC Infect Dis. 2020;20(1):1-9.

20. Woldeamanuel BT. Trends and factors associated with healthcare utilization for childhood diarrhea and fever in Ethiopia: further analysis of the demographic and health surveys from 2000 to 2016. J Environ Public Health. 2020;2020:1-16. https://doi.org/10.1155/2020/8076259.

21. Workie GY, Akalu TY, Baraki AG. Environmental factors affecting childhood diarrheal disease among under-five children in Jamma district, south Wello zone, Northeast Ethiopia. BMC Infect Dis. 2019;19(1):804. https://doi.org/1 0.1186/s12879-019-4445-X.

22. Getachew B, et al. Factors associated with acute diarrhea among children aged 0-59 months in Harar Town, Eastern Ethiopia. East Afr J Health Biomed Sci. 2018;2(1):26-35.

23. Yaya S, Ekholuenetale M, Tudeme G, Vaibhav S, Bishwajit G, Kadio B. Prevalence and determinants of childhood mortality in Nigeria. BMC Public Health. 2017;17(1):485. https://doi.org/10.1186/s12889-017-4420-7.

24. Alemayehu M, Alemu T, Astatkie A. Prevalence and determinants of diarrhea among under-five children in Benna Tsemay District, south Omo zone, southern Ethiopia: a community-based cross-sectional study in pastoralist and Agropastoralist context. Adv Public Health. 2020;2020:1-11. https://doi. org/10.1155/2020/4237368.

25. Goldstein H. Multilevel statistical models, vol. 922: Wiley; 2011.

26. Harvey G. Multilevel statistical models; 2003.

27. Larsen K, Merlo J. Appropriate assessment of neighborhood effects on individual health: integrating random and fixed effects in multilevel logistic regression. Am J Epidemiol. 2005;161(1):81-8. https://doi.org/10.1093/aje/ kwi017.

28. Merlo J, Chaix B, Ohlsson H, Beckman A, Johnell K, Hjerpe P, et al. A brief conceptual tutorial of multilevel analysis in social epidemiology: using measures of clustering in multilevel logistic regression to investigate contextual phenomena. J Epidemiol Community Health. 2006;60(4):290-7. https://doi.org/10.1136/jech.2004.029454.

29. Larsen K, Petersen JH, Budtz-Jørgensen E, Endahl L. Interpreting parameters in the logistic regression model with random effects. Biometrics. 2000;56(3): 909-14. https://doi.org/10.1111/j.0006-341X.2000.00909.X.

30. Austin PC, Stryhn H, Leckie G, Merlo J. Measures of clustering and heterogeneity in multilevel $\mathrm{P}$ oisson regression analyses of rates/count data. Stat Med. 2018;37(4):572-89. https://doi.org/10.1002/sim.7532.

31. Zuur AF, et al. Zero-truncated and zero-inflated models for count data, in Mixed effects models and extensions in ecology with R: Springer; 2009. p. 261-93.

32. Edwin P, Azage M. Geographical Variations and Factors Associated with Childhood Diarrhea in Tanzania: A National Population Based Survey 201516. Ethiop J Health Sci. 2019;29(4).

33. Ashole Alto A, Godana W, Gedamu G. Impact of Community-Led Total Sanitation and Hygiene on Prevalence of Diarrheal Disease and Associated Factors among Under-Five Children: A Comparative Cross-Sectional Study in Selected Woredas of Gamo Gofa Zone, Southern Ethiopia. Adv Public Health. 2020;2020

34. Takele K, Zewotir T, Ndanguza D. Risk factors of morbidity among children under age five in Ethiopia. BMC Public Health. 2019;19(1):942. https://doi. org/10.1186/s12889-019-7273-4.

35. Atnafu, A., et al., Geographical disparities and determinants of childhood diarrheal illness in Ethiopia: Further Analysis of 2016 Ethiopian Demographic and Health Survey 2020.

36. Ferede MM. Socio-demographic, environmental and behavioural risk factors of diarrhoea among under-five children in rural Ethiopia: further analysis of 
the 2016 Ethiopian demographic and health survey. BMC Pediatr. 2020;

20(1):1-9.

37. Pisey V, Banchonhattakit P. Influence of socio-demographic and

environmental factors on childhood diarrhea in Cambodia. F1000Research 2020;9(303):303.

38. Bogale AL. Frequency of diarrheal attack and its predictors among infants and young children from Akaki Kality sub-city: a community based study. EC Paediatrics. 2020;9:01-9.

\section{Publisher's Note}

Springer Nature remains neutral with regard to jurisdictional claims in published maps and institutional affiliations.

- fast, convenient online submission

- thorough peer review by experienced researchers in your field

- rapid publication on acceptance

- support for research data, including large and complex data types

- gold Open Access which fosters wider collaboration and increased citations

- maximum visibility for your research: over $100 \mathrm{M}$ website views per year

At $\mathrm{BMC}$, research is always in progress. 